\title{
Some Thoughts on Practising Physiotherapy in a Multi-Cultural Country
}

\begin{abstract}
Physiotherapists in South Africa are often confronted with ethical issues, which arise from the multi-cultural nature of the society. This paper discusses the ethical theory of cultural relativism in an attempt to highlight the complexities of making moral judgements across cultural, ethnic and religious boundaries.
\end{abstract}

KEY WORDS: ETHICS, CULTURAL RELATIVISM, MULTI-CULTURAL.

\section{JELSMA J ${ }^{1}$}

${ }^{1}$ Associate Professor, Deputy Head of Division of Physiotherapy, Department of Health and Rehabilitation Sciences, Faculty of Health Sciences, University of Cape Town.

\section{INTRODUCTION}

Physiotherapy students and graduates in South Africa are faced with challenges to ethical* practice on a daily basis. The fact that South Africa is a multi-cultural country, with so many socio-economic and cultural groupings, gives rise to a special set of ethical concerns. Should physiotherapists guard against imposing their own cultural and religious norms (consciously or sub-consciously) on their expectations of patient/client behaviour? Are all cultural viewpoints equally valid? Is it the duty of the therapist to warn against unsafe cultural practices or is this unethical? These are not easy questions to answer, particularly as South Africa emerges from the apartheid era in which a euro-centric cultural, religious and social viewpoint was regarded by the authorities as being the basis of moral behaviour.

An ethical theory of relevance to this debate is that of cultural relativism. Relativism is a theory that arises from the observation that people within different cultural contexts appear to regard different actions as being morally acceptable and desirable behaviour. Such observations include ancient examples

\section{CORRESPONDENCE TO:} Jennifer Jelsma

Department of Health and Rehabilitation Sciences, Faculty of Health Sciences, University of Cape Town, Anzio Road, Cape Town.

Tel: (021) 406-6402

Fax: (021) 406-6323

E-mail: jjelsma@uctgsh1.ac.za such as that of King Darius who observed that the Greeks burned their fathers as a sign of respect, whereas the Callation tribe ate their fathers, similarly to indicate their respect (Rachels, 1999). More recent examples include those of Ruth Benedict (Benedict, 1959) who concludes that behaviour which is regarded as pathological in one society (such as paranoia) might be the behavioural norm in another. The debate around genital mutilation (an emotive term) or clitorectomy in females is to a certain extent centred on this theory.

\section{WHAT ARE THE ELEMENTS OF CULTURAL RELATIVISM?}

The theory of cultural relativism states that there are no absolute, morally acceptable or unacceptable actions but that all actions can only be judged from the social context within which they take place. No moral viewpoint is necessarily correct. The locus of deciding whether an action is morally desirable resides within a certain cultural context and a specific period of history. In other words, no action can be regarded as being absolutely right or wrong, the rightness of the action is relative to a certain social, chronological and cultural context. There is thus no universal morality that applies to all human beings at all times and in all places (Bond, 1996) and morally acceptable action is basically "habitual action" (Benedict, 1959).

There is an important distinction between empirical or descriptive rela- tivism which seeks to describe the ways in which humans attempt to lead socially valuable lives and normative relativism which attempts to justify actions with reference to the values held by their own societies and historical times (Benatar, 2003, Benn, 1998, Rosada, 1990). The difference between understanding the "is" and the "ought" represents the difference between the empirical sciences, such as sociology and anthropology and ethics and this distinction can become blurred in discussion of different cultural practices. Similarly cultural relativism which is essentially concerned with societal norms, should not be confused with individual or ethical relativism in which each individual by determining what action is right for him, determines what is right (Rosada, 1990).

The theory rests on the basis that what is right depends on whether the society within which the act takes place regards the act as being morally desirable. The rightness of an act depends on whether people regard the act as right and not on an absolute standard that lies outside of that society. It maintains that no one group of people can decide for another group what is moral behaviour for the other group. Macintyre (quoted by Bond, 1996) suggests that morality is embedded in culture and moral judgements can be made, but only from the perspective of a "particular living tradition" Further, good can only be discovered in the doing, and cannot be independent from the time and place

* N ote that ethics is the study and analysis of morality and moral behaviour. It is normative, i.e. tries to identify "good" and "bad" behaviour, whereas the study of morality is descriptive. 
in which the individual finds him/herself.

It can be seen to be directly opposed to the categorical imperative of the deontologist perspective, which claims that moral values are absolute and reside entirely within the nature of the action (Benatar, 2003).

\section{CRITICISM OF THE THEORY}

There are many arguments against this theory. These include arguments against the rejection of an absolute moral standard. There are many situations in which what the majority of people within a society have believed has been/is morally unacceptable. Cultural relativism leads to the untenable position of justifying clearly immoral behaviour such as Nazism, racism and sexism on the grounds that the majority of a society believe that such behaviour is correct (Benn, 1998). In several cases the loudest criticisms of cultural relativism have come from within societies that do disregard human rights (Namazie, 1998).

Relativism would have us believe that Apartheid was morally acceptable for the majority of white South Africans because they believed that it was right. Simultaneously the majority of black South Africans believed that Apartheid was wrong, for this group morality demanded actively dismantling the structure. Moral relativism cannot aid in resolving this situation - each group is morally justified and has the right to defend their moral claim. Conflict resolution becomes impossible on moral grounds alone.

Cultures are always contested and if cultural relativism does imply that each society determines the rightness of the individual's actions, this does not allow for the moral obligation of individuals within societies to challenge unjust practices and alter these (Bacigalupo, 2000). Similarly, as the right action is determined simply by the beliefs of the society in which that action takes place, there can be no progress in moral understanding and judgement (Rachels, 1999) in response to those individuals who have contested the culture. Slavery, because it was once sanctioned in North America was morally acceptable at that time, just as it would now be wrong because it is no longer sanctioned within that society. The resulting conclusion that no moral progress has been made in this regard is clearly unacceptable and casts further doubt on to the theory.

Further issues concerning the "moral barrier" erected by cultural relativism are raised by Benn (Benn, 1998) and Midgley (Midgley, 1981). "If we may not subject other cultures to moral scrutiny, may they not criticise us? May we not praise, if we may not blame?" And finally, Midgely states, this stance prevents us from applying reasoning to the judgement of cross-cultural ethical issues, which would ultimately lead to "inaction and the losing of all interest in moral questions” (Midgley, 1981).

\section{SUPPORT FOR THE THEORY}

Apologists for the theory maintain that cultural relativism "does not imply that there is no system of moral values to guide human conduct (my emphasis). Rather, it suggests that every society has its own moral code to guide members of that society, but that these values are of worth to those who live by them, though they may differ from our own" (Rosada, 1990). Furthermore, if certain moral rules emerge within most, if not all societies, there is a strong argument that those rules are necessary for society to exist (Rachels, 1999; Rosada, 1990) Related to this, is the making of the distinction between the absolutes of right action, which hold sway within a society, and the universals of right action, which are external to any particular society. Absolutes derive from universals. "While universals transcend cultures, absolutes are the way specific cultures implement universals in their particular societies” (Rosada, 1990). Although overt behaviour might differ radically between cultural groupings, the intention of the actions might be very similar. For example, ways of greeting might be very different (a handshake, a kiss, a bow) but the intention of all of these actions is to express respect for the one being greeted.

It is acknowledged that cultural relativism can result in acceptance of gross human rights violations (e.g. Apartheid South Africa or Nazi Germany) if the mere fact of belief by a society transforms an action into a right act. However, this major flaw is circumvented by defining "absolutes" as opposed to "universal" principles as above. These universal values, which can be regarded as human rights, include respect for the sanctity of life and for the dignity and well being of other humans. If the absolutes of right action, as defined above conflict with these universal rights, then a people from another culture and society have "the right and responsibility to object to such dehumanisation and to work toward bringing about an end to such practices" (Rosada, 1990). However, this responsibility is to be undertaken in a spirit of humility, as no cultural, ethical or historical grouping has a "clean record" when it comes to the practice of human rights.

A third argument put forward by those who espouse cultural relativism is that all our experiences and interpretations of reality are culturally mediated. Rosada quotes Bidney in stating that culture is an "absolute reality in the sense that culture alone is autonomous and independent, and that all modes of human experience and thought are relative thereto because they are functions of culture and dependent on it for their form and content" (Rosada, 1990). If this is the case, cultural relativism is in fact the only possible way to interpret moral issues. Bond (1996) cites Bernard Williams as presenting a similar case in holding that it is impossible to step outside one's "evaluative perspective" and try to evaluate an action without the "cultural anchor that gave it reality and substance". Garkawe, who by quoting from the literature, emphasises the difficulty of obtaining semantic and conceptual agreement across cultures and languages.

"In order to fully understand a culture, one must be a product of that culture. A culture produces its own unique mode of thought that acts as a schematic guide for conceptual thinking ... cross-cultural equivalents for certain moral, legal and political concepts may not exist ... Even if one culture were to borrow a concept from another culture, that concept's meaning would be filtered through the first culture's unique linguistic-conceptual structure.'(Garkawe, 1995)”. 


\section{DISCUSSION AND CONCLUSION}

How can the above theoretical arguments assist therapists in making informed ethical choices in their day-to-day practice? Should the therapist report parents who do not vaccinate their children because of a religious belief? How does the therapist respond to child abuse within the family? What is his/ or her reaction to entrenched individualism which leaves the elderly without emotional and sometimes financial support, or to possible arrogance from medical practitioners who still adhere to the strict hierarchical model of health provision, originally imported from Britain? Informed consent, either for participation in research or for therapeutic intervention is another difficult issue. In many cases women might not give consent without consulting their husbands. In some cases community leaders need to give permission for research to proceed. Does this undermine the right of the individual to determine what is done to her own body and her own life? Therapists need to constantly be critical of their own moral point of view. At no time should they assume that their ethical stance is the only correct interpretation of the moral issues with which they are confronted. However, the therapist also has the right and in fact, obligation, to examine all issues of morality in the light of the overriding, universal principles of human rights. Professional ethics require that at all times therapists behave in the best interests of the patient, taking due regard of the principles of autonomy, beneficence, nonmaleficence and justice (Beauchamp and Childress, 2001). Abuse of the individual, cannot be tolerated, however reluctant the therapist may be to challenge the cultural beliefs which might condone or require these practices.

There is no simple answer to the ethics of dealing with cross-cultural issues. The following example of how a physiotherapist could apply the above ethical principles to making a decision is as follows. A physiotherapist who comes from a Moslem background is treating a child with cerebral palsy. The parents are Christian, and for religious reasons do not believe that their child should be vaccinated. As there has been a recent epidemic of measles the therapist is worried that the child is at risk of contracting the disease. The child is well nourished and the family is financially in a stable position. The therapist would need to evaluate her own moral standpoint to ensure that she is not imposing her own religious beliefs and assuming that the beliefs of the family are automatically incorrect as they do not accord with her own. However, just because the beliefs are held by the family, that does not automatically make them morally correct for that family and even within their belief system, the universals of care of the child might over ride the absolutes of not receiving intrusive medical care. Reasoned debate with the parents might therefore yield fruit. From a legal perspective, the Courts are regarded as the guardian of the child, so that in every case where the rights of the child to health and care are infringed there is not only a moral but also a legal obligation to ensure protection. However, in practice this is not easy. If the therapist were to appeal to the courts, she would loose any co-operation she might have been receiving from the family. They would feel that their autonomy has been infringed and confidentiality has been breached. Ultimately the therapist will need to weigh up the impact of her intervention in terms of the amount of good (beneficence) a measles vaccination will have (the child is well nourished, e.g.) and the amount of harm (non-maleficence) which could include breaking the relationship of trust which should exist between therapist and family, and between family members themselves.

In conclusion, the theory of moral relativism appears to be supportive of the virtues of tolerance and humility and indeed can lead us to question our own assumptions regarding morally acceptable behaviour within our own societies. The possibility that in many cases so-called moral norms may in fact be little more than a habitual approach to dealing with ethical issues and a product of our cultural upbringing should give us pause. Cultural relativism calls us to more critically evaluate our own ethical norms and behaviour and decide if alternative ways of solving life's problems should be tolerated, opposed (Blackburn, 2000) or even replace our own ways. However, the negation of universal norms of behaviour may lead to a perverse paternalism in which we abrogate the right to reasonably debate the morality of actions that take place outside our own cultural context and time.

\section{ACKNOWLEDGEMENTS}

Fogarty Foundation for the scholarship to the International Research Ethics Course at the University of Cape Town.

\section{REFERENCES}

Bacigalupo, A. M. (2000) Introduction to cultural anthropology. http://cas-courses.buffalo. edu/classes/apy/anab/apy106/index.html

Beauchamp, T. and Childress, J. (2001) Principles of biomedical ethics. Oxford University Press, Oxford, New York.

Benatar D. Lectures on International Research Ethics Course. University of Cape Town, 2003. Cape Town.

Benedict, R. (1959) In An anthropologist at work: Writings of Ruth Benedict (Ed, Meade, M.) Houghton Mifflin Co.

Benn, P. (1998) Ethics, UCL Press, London.

Blackburn, S. (2000) In The Blackwell Guide to Ethical Theory (Ed, LaFollette, H.) Blackwell, Massachusetts, pp. 38-52.

Bond, E. (1996) Ethics and human well being, Blackwell, Massachusetts, Oxford.

Garkawe, S. (1995) The Impact of the Doctrine of Cultural Relativism on the Australian Legal System, E-Law. Volume 2, Number 1 (April 1995) http://gopher://infolib. murdoch.edu.au:70/00/.ftp/pub/subj/law/jnl/el aw/refereed/garkawe.txt

Midgley, M. (1981) Heart and mind: The varieties of moral experience, St Martin's Press, New York.

Namazie, M. (1998) In Forum on women's rights in Iran. Toronto, Canada.

Rachels, R. (1999) The elements of moral philosophy, McGraw Hill, Boston, London, Sydney, Singapore.

Rosada, C. (1990) The Concept of Cultural Relativism In a Multicultural World (Or Teaching the Concept of Cultural Relativism to Ethnocentric Students).http://www.rosada. net/articles-relativism.html 